\title{
Food Preparation at Home an Example of New Practical Strategies in the Swedish Municipal Food Service - A Qualitative Study
}

\author{
Zada Pajalic ${ }^{1}$ \\ ${ }^{1}$ School of Health and Society, Kristianstad University, Sweden \\ Correspondence: Zada Pajalic, School of Health and Society, Kristianstad University, Sweden. E-mail: \\ zada.pajalic@hkr.se
}

Received: September 4, 2013 Accepted: October 23, 2013 Online Published: October 28, 2013

doi:10.5539/jfr.v2n6p72

URL: http://dx.doi.org/10.5539/jfr.v2n6p72

This study was funded by Lund municipality and Kristianstad University, Sweden

\begin{abstract}
The purpose of the present study was to describe how one of 290 Swedish municipalities improved its FS service by terminating their earlier service of food distribution (FD) which was the delivery of ready cooked meals produced at a central kitchen in the community and introducing food preparation at the client's home. The revised system is referred to as the new FS. This study was performed using an action research approach. The data was collected by individual- and group interviews and through participatory observations. The transcribed interview material was analysed using qualitative content analysis. The $(\mathrm{n}=30)$ subjects were recruited The findings of this study revealed that the new FS was experienced as being a good service, that the new municipal FS met individual needs in a better way and that the elderly recipients could participate more actively in planning and preparing their meals. In conclusion, it was found that having their food prepared at home was considered by many of the recipients to be synonymous with individually adjusted help. The results of the study could have implications for nursing, public administration and gerontology.
\end{abstract}

Keywords: action research, elderly people, home-living, food service, municipality, qualitative research

\section{Introduction}

In Sweden the municipal food service (FS) for elderly people living at home is a part of the municipal public social and care service. The objective of this service is to ensure proper food intake for persons who are unable to do their own shopping, and prepare their own meals. This means that the Swedish welfare system takes on the responsibility for its citizens when they have a legal social related need of care. Each municipality follows the general guidelines issued by the government but may determine its own way of organising the municipal FS according to its own circumstances. The organisation of the public social and care service in Sweden, of which the food service (FS) is one part, often differs from other welfare states, primarily due to the fact that the public social and care service is based on a State instituted legal obligation to help persons in need, and is financed by taxation (Elmér, 2000). This statutory obligation is regulated by two acts of parliament: The Health and Medical Service Act and The Social Service Act (Grönwall \& Holgersson, 2000; Raadu, 2011). Each municipality in Sweden $(\mathrm{n}=290)$ has the responsibility to offer this service and may organise it as they wish. The fundamental requirement for a citizen to be granted the municipal FS is that they have a significant need of help as they are unable to fulfill their meal requirements themselves due, for example, to illness related physical or psychological limitations resulting in their being unable to do their own shopping and to prepare their own meals (Pajalic \& Westergren, 2013a; Porter, 2007).

Today, about 60000 elderly persons use the community FS service (Berensson, 2009). The FS can be organised in various ways such as the distribution of ready prepared cold meals, warm meals, and the offer of help to buy daily food requirements, mealtime support and preparing food in the home of the client. The distribution of ready prepared meals is the most common way the FS service is used. Based on population prognosis and the increase in the number of persons over 65 years (SCB, 2009) the Swedish social services try to meet future challenges by new ways of thinking related to helping the elderly with their food requirements (Engelheart \& Åhlfeldt, 2009). Further, there is demand for each municipality to use its economic resources in the best way and that the funds 
should be distributed in accordance with the needs and used in a way that shows respect for good economical housekeeping (Lundgren, 2011). This reality means that the municipalities in Sweden must work hard towards finding sustainable solutions for the future in order to resolve the situation for those with the greatest need of help. This means taking action to deal with the general expansion of the number of clients who have basic social and care requirements (Lagergren et al., 2004). The public home care officers implement a specific assessment strategy to determine what type of FS an individual person requires and how much time should be accorded for each type of service required to help each individual client (Pajalic, 2013a). The range of ready prepared foods available is virtually unlimited and the quality deemed sufficient, a wide range of restaurants and supermarkets offer a large number of different meals ,both hot, cold and frozen. There is an extensive range of ready-made meals in disposable packages that can be supplemented with fresh bread, salad, vegetables and beverage, to make up full meals. This means that today there exists many alternative ways to satisfy the food requirements of the elderly that offer them greater opportunity to decide what they wish to eat and when (Lundgren, 2011).

A literature review revealed that there is no existing research material focusing on how elderly people living at home experience the new food service i.e. having their food prepared in their home.

\section{Aim}

The aim of the present study was to describe how one Swedish municipality improved their FS in order to put the individual at the centre and to meet their needs in a more holistic way.

\section{Method}

\subsection{Context}

The study was conducted within an average-sized municipality of about 120000 inhabitants situated in southern-east part Sweden. Total number of inhabitants in Sweden is about 9000000 (SCB, 2009). Approximately 190 elderly people, living in the municipality, used the new municipal FS where the preparation of meals is done in the recipient's home. Thereby, the earlier service based on the distribution of ready prepared hot meals was terminated. The municipality began their new FS evaluation work during 2004 and concluded that the municipality could not offer the same subsidised service to all citizens. The situation at the time was that the municipality only offered cold meals delivered once a week to elderly citizens living in the town centre and daily distribution of warm meals to those living in rural areas within the community. Distribution of ready-made-meals was perceived as an old fashioned service form that was founded during the period when the range of restaurant sand the availability of ready-made meals at grocery stores was not considered satisfactory. Based on this background the municipality decided that food distribution of ready-made meals should be replaced by food making in the homes of the elderly FS recipients. Those elderly, whose need of help was relatively low were offered help with buying groceries or to visit nearby restaurants if there was a need for this service. The supply of special diets should remain a municipal responsibility backed by medical and nursing evaluation by a district nurse. To cope with the new service, new routines for food and mealtimes were issued to the responsible personnel. The aim with the new routines was to establish good basic hygiene, food hygiene, and offer guidelines for the menus, food purchasing and the preparation of meals with sufficient energy and nutrition content.

\subsection{Participants and Data Collection}

This study has been carried out in spring 2013. The participants in this study were purposefully selected by a key person employed by the municipality. The selection criteria were that the participants should be personnel involved in the municipal FS at various levels, such as public home care officers, assistant nurses, and decision-makers at both administrative and political levels. Further, the study included two different groups of end users: 1) those who currently have their meals prepared in their home and who had previously had hot meals delivered from a central kitchen, 2) those who currently have municipal assistance with the purchase of prepared dishes and groceries and 3) former users who earlier had their meals supplied through the community distribution service but were re-assessed on the basis that they did not have a great enough need for municipal food support and were therefore required to solve their meal requirements themselves.

The data for this study was collected using semi-structured, individual (Kvale, 2007) and group interviews (Morgan, 1988) and observations (Spradley, 1980). Individual interviews were chosen as the data collection method as the aim was to describe and gain insight into the participant's experiences, to hear them express their point of view in their own words and what they thought was important to them (Kvale, 2007). Participant observations were chosen to gain insight into the FS process and its parts (Spradley, 1980; Stringer \& Genat, 2004). The present study was performed using an action research approach (Pajalic \& Westergren, 2013b; Stringer \& Genat, 2004) with focus on self-reflective aspects and the participants' specific expertise (Pajalic \& Westergren, 
2013b; Stringer \& Genat, 2004). Included in the collected data were individual interviews with elderly persons $(\mathrm{n}=8)$, group interviews with various professionals as public home officers and assistant nurses $(\mathrm{n}=18)$ and the results from participatory observations during the meal preparation in the elderly people's homes $(n=4)$. The transcribed interview material and notes from observations were analysed using qualitative content analysis (Krippendorff, 2004). The questions used (Table 1) were given to the participants at the start of the interview which took between 30-70 minutes. The data was collected by the author (ZP) using a tape-recorder.

Table 1 Questions used in the interviews

Can you describe the municipal FS as you experience it?

What are the strengths or weaknesses of the new FS service from your point of view?

What is most important point to satisfy with the FS service from your perspective?

How would you wish to see FS organised?

\subsection{Data Analysis}

For this study manifest content analysis was used for analysis of the transcribed interview texts and notes from the participant observations (Krippendorff, 2004; Pajalic, Persson, Westergren, Berggren, \& Skovdahl, 2012; Pajalic, Persson, Westergren, \& Skovdahl, 2012b; Spradley, 1980). Qualitative content analysis is an interpretation process that focuses on similarities and differences in various parts of the transcribed text (Krippendorff, 2004). The analysis process began with reading the transcribed interviews and notes from the observations with an open mind in order to get a feeling of the whole and to create ideas for continued analysis with the aim of the study as the basis. The meaning units were then identified and condensed into codes. The analysis process focused on a description of what is clear and visible in the text. The next level of the analysis was to observe the dialectical movements between the whole and the parts and between understanding and explanation. Then a critical reflection over the codes was made and these were compared with aim of the study. Then the subcategories and categories were sorted and discussed in relation to the aim (Pajalic, 2013b). Finally the preliminary results were reconnected to the participants for member checking (Lincoln \& Guba, 1985).

\subsection{Ethical Considerations}

The study was performed in accordance with the Helsinki Declaration (Saif, 2000), and has been examined by the Regional Ethical Review Board in Lund, Sweden (LU12/699). All participants gave their informed consent to participate after having been presented with detailed information about the study and their own participation. They were also informed that they had the right to terminate their participation at any time without it having any consequences for them.

\section{Results}

\subsection{Introduction of the New FS}

In the autumn of 2011, the decision makers decided that the new FS system should begin during April 2012. During September-October 2011 all elderly persons involved in the current FS system received written information explaining how the current service would be terminated and replaced with a new FS system based on the preparation of meals in the homes of the elderly clients and that it would require a new needs assessment which would be carried out by a community home care officer during a visit to the client's home

One of the participants noted that: "In the old food service, all assistance decision has been suspended, we made no reassessments and it could happen to those who needed this service become better but still chose to retain this service. What is new with the new form of service is that we are time-limited aid decision up to a year and do a new review. Further another argument was that we could not offer the same food services to all our citizens. Some were given food once a week and daily. Now it's the same food service to all".

All those persons who were users of the FS system where sent a letter with a reply form, asking them to choose between four alternatives which were: 1) Do you wish to have a new assessment for your entitlement to the new FS system? 2) Would you prefer to use another means of food supply i.e. from a private source outside the municipal service? 3) Would you like to have assistance from the municipality when shopping for groceries from which you would prepare your own meals? 4) Would you rather not have the municipal food service?

One of the participants described it as: "The introduction of the new FS i.e. food making at home raised concern, 
there were many who had points of view on how it should be organised. There was nobody interested in preparing clients meals at home. Many of users expressed that they don't want strange people in their kitchen, rather they preferred the distribution of ready prepared meals". Especially, the most skepticism was voiced by those who had food distribution daily and their relatives. Fortunately, although at the beginning many of the participants were skeptical towards the new FS, over time they developed a more positive attitude.

\subsection{Strengths of the New FS}

All of the participants in the present study expressed that they were positive towards the new FS system and that they really needed this service. Initial negative attitudes had changed and those receiving the new FS service felt satisfied. One of participants described it in the following way: "Some of them (elderly users and their relatives) had a negative attitude in the beginning but now they signal that the new FS is a good solution and that most of the users are very satisfied. I think that things have become better and more fair as those who really need the service can get it. Now it is the real need that is satisfied and not just a service, the new FS is more based on client participation".

As additional strengths in the new FS it was put forward that for the client it is positive to be able to have meals prepared in their own home since pre-prepared meals can never replace home cooked food. Food preparation was described by the participants as a social activity where those involved can get together in the planning and implementation of meal preparation. As one of the participants expressed: "while preparing the clients meal one can ask what do you think? Does it taste and smell good? There is the occasion for conversation while the food is being prepared". The competence of the cook to prepare food was described as important. One of the participants described the eventual lack of this competence as: "If the designated person from the community cannot cook then it boils down to frozen meatballs in the microwave". Conclusively, all the participants agreed that new FS is a service with huge possibilities and that in this matter the municipality had shown great ambition and that new FS is associated with better life-quality.

\subsection{Food Preparation at Home Is Synonymous With Proper Food}

One of participants expressed that dish variation is presently dependent on the person who prepares the food, their knowledge and fantasy. Mealtimes can be steered to some degree by the personnel. The quality of mealtimes was described as being based on how the food is prepared. If the food is prepared using good quality ingredients it will inevitably lead to significantly better nourishment, and it is the consumers who choose the ingredients. The new FS was described as a service that brings greater variation in nourishment, taste and the appearance of the prepared meal and that was the reason why the end users preferred it. Those persons interviewed, who represented the personnel described how the FS users enjoy having food prepared in their homes especially those who have not had food prepared at home since a long time. Among other things, they enjoyed the smell of cooking. The interviewed participants representing the users who chose the distribution of unsubsidised prepared meals from an external company described how they were satisfied with this service. One of them expressed: "I do not have anything negative to say about that". Contrary to this, some expressed that they were disappointed over the municipality's decision to close down the prepared meal service because the alternative was much more expensive for the elderly than the municipal food service.

\subsection{Challenges With the New FS}

The participants among the FS personnel described how they had learnt much during the practical part of the introduction of the new FS. They described that the new service requires planning with focus on the menus for each day or week and that shopping for groceries demands planning and coordination because these moments involve different persons. Preparation procedures before food making are dependent on which personnel are on the work schedule. They described how they started by planning the first visit to a client in the morning while collecting the ingredients for the day's meal. Sometimes it is task of the client to take the ingredients from the fridge or freezer. Many participants among the FS personnel described how they often need to improvise and find alternative solutions because it often happened that the right ingredients were missing

Regarding experiences related to food making at the clients home the participants described how there was a small group of personnel who do not like to prepare food as they find the task uninteresting. This attitude has a negative influence on the overall quality of the new FS. One participant described it as: "There are many in our group who cannot prepare food, they think that if there is food in the freezer they need not bother to prepare fresh food".

One of the participants noted that it was not acceptable that some personnel chose not to cook the clients meal and that this is a matter for the client to decide not the FS staff. It was stressed that the role of the manager was 
to ensure that the personnel carried out their instructions fully. Furthermore, the participants agreed that the negative attitudes among some of their colleagues were due to their lack of knowledge and understanding of all the parts involved in servicing home cooking and their difficulty to appreciate the service. If the client chooses an unbalanced diet the staffs tries to add more variety. All the participants agreed that the clients who have their meals prepared in their home eat more. Furthermore, the staff observed that the elderly clients enjoy their company at mealtimes. One of participants described in the following way: I continue to cook while the client eats; I'm working on making good use of my time.

To get some idea of the personal results of the meals, weight checks are offered. There is a particular focus on clients who show weight loss. The staff noted that often they will continue to cook while the client eats in order to make good use of their time when preparing the planned courses. One participant noted that it was important not to give the client the impression that they were anxious to be finished and to leave as soon as possible as this can affect the client's appetite.

\section{Discussion}

\subsection{Methodological Considerations}

Findings from this study are evaluated in terms of credibility, dependability and transferability (Lincoln \& Guba, 1985). Credibility was assured by presenting views from different participants in order to capture their different experiences. Dependability was assured by the fact that the same researcher, the author, carried out all the interviews, observations and transcriptions. The use of a tape-recorder and verbatim transcripts, as well as referring back to and re-reading the transcripts during the analysis process, allowed the researcher to remain close to the text. The citations make it possible to assure conformability. Transferability can be considered to be achieved by the way that the study results can be transferred to different contexts. The preliminary results were reconnected to the participants for member checking (Lincoln \& Guba, 1985).

\subsection{Discussion of the Results}

The present study shows that the introduction of the new FS undertook a process from initial doubt of the personnel to positive evaluation. The positive evaluation of the personnel was shown in another study that the attitudes of professionals in relation to the introduction of something new in their daily routines is related to their professional background (Christensson et al., 2010; Landstrom, Sidenvall, Koivisto Hursti, \& Magnusson, 2007; Scott-Samuel \& Springett, 2007; Westergren \& Hedin, 2010). Those professionals who have a higher educational and professional background and level of possibility to see the big picture and the possible benefits of a new service are more optimistic (Landstrom, et al., 2007). Furthermore Cramm et al. (2012) showed that on-going identification of effective improvements is of importance for the quality of the care for persons with chronic conditions (Cramm, Rutten-Van Molken, \& Nieboer, 2012).

Another study showed that nutrition study circles and a nutritional care policy improve nutritional care in both the short- and long-term perspective (Westergren \& Hedin, 2010). The present study shows that there is still a need to work on routines and ways of changing any negative attitudes among the personnel related to food preparation as a work task. This result was confirmed in another study that showed the importance of continuously developing professional knowledge in nutrition, inter-professional communication and a comprehensive view over the consequences of FS as a whole (Pajalic, 2013a; Pajalic, Persson, Skovdahl, \& Westergren, 2012; Pajalic, Persson, Westergren, \& Skovdahl, 2012a). Furthermore it was shown that communication between various professionals is of importance for inter-professional collaboration (Nuno-Solinis, Berraondo Zabalegui, Sauto Arce, San Martin Rodriguez, \& Toro Polanco, 2013). Transfer of accurate information related to care users between various organization levels and professionals is needed (Olsen, Hellzen, \& Enmarker, 2013). Furthermore Macadam found in her study (2011) that there is need to develop and strength linkage between various care giver organizations in aim to integrate care for the elderly people (Macadam, 2011).

The present study shows that the new FS is more holistic and positively influences the life quality of the receivers. This is confirmed by results from other studies were it is shown that relatives of the municipal FS service users advocate a food preparation service in the home of the recipient reasoning that food preparation at home creates a real sense of homemade food and of being at home. Further, the studies highlighted the importance of the social aspects of the new FS that relieves loneliness and isolation among the recipients living alone and without frequent contact with other people (Pajalic, 2013c; Pajalic et al., 2012b). Another study showed that an individual's experiences are important because these experiences in combination with those of the FS personnel are important when promoting a holistic view on nutrition and better quality of life for individuals requiring help with meal preparation needs related to food intake (Odencrants, 2008). 
The present study showed that food prepared at home is more adjusted to the individual. The results of other study results confirmed this and showed that FS receivers needs and rights could be achieved and that systematic work with positive personnel can be of value in the modification of municipal services to better meet individual needs (Pajalic, Skovdahl, Westergren, \& Persson, 2013; Pajalic \& Westergren, 2013a). Another study showed that a social network including individually adjusted help had a positive influence on the life quality of elderly people living alone (Hellström, 2003). Florin (Florin, 2007) showed in his study that care personnel need to be aware of the care receiver's preferences for participation in social and care services in order that they can plan their actions in accordance with care receivers preferences to the degree preferred by them (Florin, 2007). The results showed that municipal FS should be seen as inter-operability issue. Everyone concerned needs to be involved in the planning for improving the municipal FS, including the receivers. It is important that the involved professionals should have the possibility to emanate from their professional roles when participating in planning for positive development. The involved personnel's role continuously requires the development of their knowledge in nutrition, which also applies to both the involved professionals and the food service receivers. In conclusion, introduction of new routines appeared to arouse initial skepticism which can depend on the professional's attitudes and level of competence. The level of competence appears to be important for the individual's ability to monitor the whole picture of the new FS. It appears that food preparation at home is considered to be synonymous with individually adjusted assistance.

\section{Conclusion}

This study indicates that the new FS was experienced as good service and that new FS can meet individual need in a better way than distribution of ready meals. The elderly people can participate more actively in the planning and preparation of their meals. The personnel who prepare the food at elderlies home need continuous, updated knowledge regarding nutrition. Further the manager's role was stressed as being important for the continuous development in order to influence the FS personnel's attitudes related to food preparation as being an important task.

\section{Acknowledgments}

The author is grateful to all participants for their interesting input and inspiring dialogue. Thanks to Birgitta Åkerson, Seth Petersson and Vård- ochomsorgsnämnden Lund municipality Sweden for initiating and welcoming this research.

\section{Relevance to Practice}

This study indicates that small changes in FS can meet practical and nutritional needs for elderly people. The new service seems to be more holistic in comparison with distribution of ready meals including other benefit as breaking the elderly's social isolation. Furthermore the elderly are actively involved in food making process that my strength their feelings of participation and being part of social context. Furthermore the FS needs to be continuously improved towards offering continuous knowledge development with focus on elderly's nutrition needs.

\section{References}

Berensson, K. (2009). Comparisons of 2009. PUBLIC HEALTH (in Swedish: Öppna jämförelser 2009. Folkhälsa). Stockholm: Sveriges kommuner och landsting (SKL).

Christensson, L., Bjorklund, A., Ahnby, U., Henrikson, M., Joakimson, D., \& Henning, C. (2010). Attitudes of different professionals toward the well-being of older adults living at home. J Allied Health, 39(4), 293-300.

Cramm, J. M., Rutten-Van Molken, M. P., \& Nieboer, A. P. (2012). The potential for integrated care programmes to improve quality of care as assessed by patients with COPD: early results from a real-world implementation study in The Netherlands. Int J Integr Care, 12, e191.

Elmér, Å. (2000). Swedish social politics (in Swedish: Svensk socialpolitik). Lund: Studentlitteratur.

Engelheart, S., \& Åhlfeldt, E. (2009). Mat och ätande för äldre : en handbok för dig som arbetar med vård och omsorg om äldre. Haninge: Nestor FoU-center.

Florin, J. (2007). Patient participation in clinical decision making in nursing: a collaborative effort between patients and nurses. Örebro: Örebro universitetsbibliotek.

Grönwall, L., \& Holgersson, L. (2000). Socialtjänstlag 2000: med kommentarer. Stockholm: Gothia.

Hellström, Y. (2003). Quality of life in older people receiving ADL help: help, help providers, and complaints. Lund: Univ. 
Krippendorff, K. (2004). Content analysis : an introduction to its methodology. Thousand Oaks, Calif.: Sage.

Kvale, S. (2007). Doing interviews. Thousand Oaks, Calif.: Sage Publications.

Lagergren, M., Fratiglioni, L., Hallberg, I. R., Berglund, J., Elmstahl, S., Hagberg, B., ... Wimo, A. (2004). A longitudinal study integrating population, care and social services data. The Swedish National study on Aging and Care (SNAC). Aging Clin Exp Res, 16(2), 158-168. http://dx.doi.org/10.1007/BF03324546

Landstrom, E., Sidenvall, B., Koivisto Hursti, U. K., \& Magnusson, M. (2007). Health-care professionals' perceived trust in and willingness to recommend functional foods: a qualitative study. Appetite, 48(2), 241-247. http://dx.doi.org/10.1016/j.appet.2006.09.008

Lincoln, Y. S., \& Guba, E. G. (1985). Naturalistic inquiry. Beverly Hills, Calif.: Sage.

Lundgren, S. (2011). Maten i hemvården - framtida inriktning, 2011-02-03 Tjänsteskrivelse, Dnr VOO 2011/0029.

Macadam, M. (2011). Progress toward integrating care for seniors in Canada: "We have to skate toward where the puck is going to be, not to where it has been". Int J Integr Care, 11 Spec Ed, e016.

Morgan, D. L. (1988). Focus groups as qualitative research. Newbury Park, Calif: Sage Publications.

Nuno-Solinis, R., Berraondo Zabalegui, I., Sauto Arce, R., San Martin Rodriguez, L., \& Toro Polanco, N. (2013). Development of a questionnaire to assess interprofessional collaboration between two different care levels. Int J Integr Care, 13, e015.

Odencrants, S. (2008). The complexity of nutritional status for persons with chronic obstructive pulmonary disease : a nursing challenge. Örebro: Örebro universitetsbibliotek Örebro University Library.

Olsen, R. M., Hellzen, O., \& Enmarker, I. (2013). Nurses' information exchange during older patient transfer: prevalence and associations with patient and transfer characteristics. Int J Integr Care, 13, e005.

Pajalic, Z. (2013a). How public home care officers reason when making a needs assessment for food distribution to homebound elderly persons in Sweden. Global Journal of Health Science, 5(5), 31-40. http://dx.doi.org/10.5539/gjhs.v5n5p31

Pajalic, Z. (2013b). Matdistribution till hemmaboende äldre personer ur flera perspektiv. Örebro universitet, Örebro. Retrieved from http://urn.kb.se/resolve?urn=urn:nbn:se:hkr:diva-10378

Pajalic, Z. (2013c). The Swedish Municipal Food Distribution Service to the Elderly Living at Home as Experienced by the Recipient's Relatives. Global Journal of Health Science, 5(6), 12-18. http://dx.doi.org/10.5539/gjhs.v5n6p12

Pajalic, Z., Persson, L., Skovdahl, K., \& Westergren, A. (2012). Facilitating Change, the Decision-maker's Views of Municipality Organized Food Distribution to Elderly People Living at Home and Suggestions for Development-A Participatory Action Research Study. Public Administration Research, 1(1), 14-23.

Pajalic, Z., Persson, L., Westergren, A., Berggren, V., \& Skovdahl, K. (2012). The experiences of elderly people living at home related to their receiving meals distributed by a municipality in Sweden. Journal of Food Research, 1(1), 68-78. http://dx.doi.org/10.5539/jfr.v1n1p68

Pajalic, Z., Persson, L., Westergren, A., \& Skovdahl, K. (2012a). Evaluation for change, the decision maker's involvement in the development of Food Distribution to home living elderly people. Paper presented at the International Conference Interprofessional Partnership: Improvement for Global Health Outcomes Thailand. http://urn.kb.se/resolve?urn=urn:nbn:se:hkr:diva-9153

Pajalic, Z., Persson, L., Westergren, A., \& Skovdahl, K. (2012b). Public home care professionals' experiences of being involved in food distribution to home-living elderly people in Sweden: a qualitative study with an action research approach. Journal of Nursing Education and Practice, 2(2), 41-51. http://dx.doi.org/10.5430/jnep.v2n2p41

Pajalic, Z., Skovdahl, K., Westergren, A., \& Persson, L. (2013). How the professionals can identify needs for improvement and improve Food Distribution service for the home-living elderly people in Sweden-an action research project. Journal of Nursing Education and Practice, 3(8), 29-40. http://dx.doi.org/10.5430/jnep.v3n8p29

Pajalic, Z., \& Westergren, A. (2013a). Part 1 Food distribution for the elderly, in Swedish (Del 1Matdistribution till äldre). In L. Jakobsson (Ed.), Action research in health and social care - the application and theory, in Swedish (Aktionsforskning $i$ vård och omsorg - tillämpning och teori) (Vol. 1.1). Malmö: Glerupps. 
Pajalic, Z., \& Westergren, A. (2013b). Part 2 Action research bases in Swedish (Del 2 Aktionsforskningens grunder). In L. Jakobsson (Ed.), Action research in health and social care - the application and theory, in Swedish (Aktionsforskning i vård och omsorg - tillämpning och teori) (Vol. 1.1). Malmö Glerupps.

Porter, E. J. (2007). Problems with preparing food reported by frail older women living alone at home. Advances in Nursing Science, 30(2), 159-174. http://dx.doi.org/10.1097/01.ANS.0000271106.42043.be

Raadu, G. (2011). Författningshandbok för personal inom hälso- och sjukvården. $2011=42$. uppl. Stockholm: Liber.

SCB. (2009). Sveriges framtida befolkning 2009-2060. Stockholm: Statistiska centralbyrån (SCB).

Scott-Samuel, A., \& Springett, J. (2007). Hegemony or health promotion? Prospects for reviving England's lost discipline. J R Soc Promot Health, 127(5), 211-214. http://dx.doi.org/10.1177/1466424007081786

Spradley, J. P. (1980). Participant observation. New York: Holt, Rinehart and Winston.

Stringer, E. T., \& Genat, W. J. (2004). Action research in health. Upper Saddle River, N.J.: Merrill Prentice Hall.

Westergren, A., \& Hedin, G. (2010). Do study circles and a nutritional care policy improve nutritional care in a short- and long-term perspective in special accommodations? Food Nutr Res, 54.

\section{Copyrights}

Copyright for this article is retained by the author(s), with first publication rights granted to the journal.

This is an open-access article distributed under the terms and conditions of the Creative Commons Attribution license (http://creativecommons.org/licenses/by/3.0/). 